\title{
When the 12th Man Throws a Flag: Fan Attitude Toward the Proposed Globalization of the NFL: An Abstract
}

\author{
Eldrede Kahiya and Nina Krey
}

\begin{abstract}
Over the past year, the National Football League (NFL) has been exploring ways of increasing its international footprint. This paper focuses on the NFL's proposed international expansion into Mexico. Specifically, the study examines fan reaction to the prospect of hosting games in Mexico City. From a theoretical perspective, we pit the generic international marketing discourse, which projects a positive outlook on globalization, and the sociological perspective, which takes a cynical view of globalization. Unlike past research which has adopted a historical perspective, our data are real time and drawn from fan comments to a recent sports headline announcing the plans for international expansion. An analysis of fans' comments shows that the "NFL" invokes different images including a league, a game, or a sports brand involving teams, host cities, fans, players, and the NFL Commissioner. Themes drawn from comments indicate that the majority of fans are protesting the proposed international expansion followed by those bargaining (with) and denigrating it. Those shielding (i.e., supporting) it are represented to a much lesser extent. The results generally depict that fans are anti-internationalization. While the basis for the resistance can be tied to the anti-global sentiment (e.g., anticommodification, exceptionalism, nationalism), there is a clear cognitive rationale underlying some of the fans' concerns. From the perspective of a front office executive, our results suggest the NFL has some challenges to surmount for international expansion to gain support from American fans and be successful.
\end{abstract}

\footnotetext{
E. Kahiya $(\bowtie)$

Victoria University of Wellington, Wellington, New Zealand

e-mail: eldrede.kahiya@vuw.ac.nz

N. Krey

Rowan University, Glassboro, NJ, USA

e-mail: krey@ rowan.edu
} 